\title{
EAI Endorsed Transactions

\section{Philosophy of Computer Game with BCI as Healthcare Information Design Outcomes: Toward a New Approach of Knowledge Game}

\author{
Hyunkyoung Cho ${ }^{1, *}$ and Joonsung Yoon ${ }^{2}$ \\ ${ }^{1}$ Design Institute, Inje University, Korea hkcho.vt.edu@gmail.com \\ ${ }^{2}$ Tianjin Normal University/Global School of Media, Soongsil University, Korea dryoon@maat.kr
}

\section{Abstract}

This study presents that the computer game using brain information as healthcare design outcomes is being philosophized as an object of thoughts. In order to define the philosophy of computer game with BCI (Brain-Computer Interaction), my paper examines Racing Car Game using EEG (electroencephalography) as healthcare information design outcomes and reconsiders the rule and use of BCI game in the conflict between the game and the narrative. It proposes that the BCI game using brain waves as bio-information originated from healthcare design reframes traditional philosophical discourses in knowledge game and contributes to the ecology of networked knowledge enabling new forms of collaborations between sciences, engineering, arts, and design.

\begin{abstract}
Keywords: Knowledge Game, Philosophizing BCI Game, Brain-Computer Interaction, Healthcare Information Design, Rule, Use.
\end{abstract}

Received on 20 November 2016, accepted on 04 September 2017, published on 09 October 2017

Copyright (C 2017 Hyunkyoung Cho and Joonsung Yoon, licensed to EAI. This is an open access article distributed under the terms of the Creative Commons Attribution licence (http://creativecommons.org/licenses/by/3.0/), which permits unlimited use, distribution and reproduction in any medium so long as the original work is properly cited.

doi: 10.4108/eai.8-11-2017.153332

\section{Introduction}

Decolonizing knowledge is an awakening of disciplines in knowledge game. Knowledge is acquired through complex cognitive processes and conducting by correcting and training disciplines. Like computer game, it is justified by a power of theoretical or practical understanding system and can be more or less formal or systematic. To decolonize knowledge of computer game is to invaginate game studies into the ecology of networked knowledge enabling new forms of collaboration between sciences, engineering, arts, and design. It is concerned with both conceptual and methodological strategies aimed at understanding and enhancing the processes and outcomes of collaborative research in knowledge game.

According to Hannah Arendt's action theory, the knowledge is the way in which we humans produce our

\footnotetext{
${ }^{*}$ Corresponding author. Email:hkcho.vt.edu@gmail.com
}

means of life. It articulates itself in the mode of performing our life beyond the material and physical one. The knowledge condition is a whole from the perspective of the idea of social relations embodied in the real movement of life.

Max Horkheimer and Theodor W. Adorno also meditated the knowledge as the intertwinement of reason and experience in the actual life-process. They point out a paradox of knowledge embracing both enlightenment and myth. The knowledge has the twofold character of enlightenment traversing the universal movement of mind and a nihilistic, life-denying power [1]. On the one hand, we humans create our own knowledge condition, and on the other, everything we create turns immediately into a condition. This presents that the knowledge condition can be transformed by the performing of the action. Here's the problematic of knowledge of computer game.

Like human-human communication, technology and humans act and react. In particular, computational 
technology is endowed with highly intelligent and perceptive qualities; has its own laws; and the system itself evolves. With the ability of autonomy and emergence, technology performs the autonomous and emergent action beyond human control. It becomes 'a performer (a collaborator)' collaborating with humans [2].

Technology as a performer (collaborator) transforms the knowledge condition. The transformation, the expanded knowledge conditions by the collaborative action of we humans and technology can be called as "We" human-and-technology [3]. The word of "We" human-and-technology indicates that knowledge of we humans is organized by collaborative actions between we humans and technology. "We" human-and-technology is a response to the need for alternative frames of reference to inter-active systems design and alternative ways of understanding the relationships and collaborative actions between humans and new digital technologies [4]. The concept provides a chance to study a growing interest in the philosophizing computer game with interactive technologies.

\section{What The Computer Game is Philosophizing}

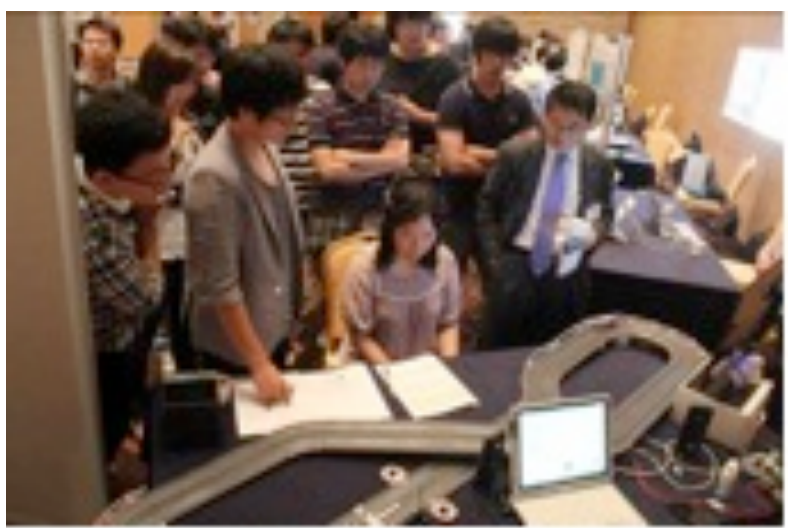

Figure 1. $\mathrm{BCl}$ Game using Brain Information as Healthcare Design Outcomes:

Racing Car Game with BCl: designed by BioComputing laboratory at GIST, Korea, EPOC and Carrera Slot Car

\subsection{Philosophizing BCl Game as Healthcare Information Design Outcomes}

Human-Computer interaction (HCI) techniques evolve from conscious or direct inputs. As an emerging field in HCI, Healthcare Information Design indicates applications of bio-information originated from healthcare design such as BCI (Brain-computer Interaction) through EEG (Electroencephalography), HCI using EMG (Electromyography). Especially, BCI technologies are based on Brain Information as healthcare information design outcomes. The computer game using brain information for Human-Computer Interaction shows that the collaborative action of "We" human-and-technology involves both conscious and non-conscious inputs. It expands the collaborative action into a kind of biofeedback in terms that interaction between we humans and computer is based on non-visible and non-physical bio-informations. It suggests the brain signal processing as a new way for the collaborative action of "We" humanand-technology.

For example, Racing Car Game (Fig.1) as an ongoing research-led practice about the computer game design with BCI is constituted by the concentration between human and computer as collaborators. The braincomputer collaborative action changes the car's velocity; it can improve the attention state; when the collaboration between human and computer gets stronger, the concentration level goes higher. In Racing Car Game, brainwave is the key measure. It represents the concentration as the degree of collaborative action of "We" human-and-technology. Car's velocity shows the concentration level using electroencephalography (EEG). EGG is an electrophysiological monitoring method to record the electrical activity of the brain. The concentration is observed in Beta wave and falls in the range of $14-30 \mathrm{~Hz}$.

As a new way of computer game design for "We" human-and-technology, the collaborative action through brain activities allows us a communication without physical and visible movement between human and computer. Brain signals create a new philosophical dimension of computer game design constituted by the collaborative action of "We" human-and-technology.

BCI using brain information in healthcare design is decolonizing and redefining knowledge of game in new ways. Especially, BCI as healthcare information design outcomes triggers a whole series of basic questions that how does human thinks with a computer, what is the difference between animate and inanimate, human and non-human. In the work, Racing Car Game, BCI system is closer to a tool as an extension of the human body in that human provides the rhythm. On the other hand, it is more independently active than a tool. It works automatically and imposes its rhythm on we humans. It presents that BCI as healthcare information design outcomes is non-transparent. It provokes a discrepancy that nevertheless the computer is inanimate, in practice it acts as a living and thinking object. Here's the eloquence of philosophizing computer game with BCI in HCI.

Philosophy is not a theory but an activity. Bertrand Russell meditates that the object of philosophy is the logical clarification of thoughts. The result of philosophy is not a number of 'philosophical propositions', but to make propositions clear. It should make clear and delimit sharply the thoughts which otherwise are, as it were, opaque and blurred [5]. Today the computer game with BCI as healthcare information design outcomes is not only as a major media but also as an object of philosophy 
that generates a number of discourses. It shakes the tradition of Cartesian coordinating system, through the traversing body and mind, reason and sense, the real and the virtual. It asserts the multiplicity of human existence. It maintains that there are other dimensions of human existence.

\subsection{Metaphor Performance: Rule of $\mathrm{BCl}$ Game}

BCI game using brain information originated from healthcare design is to define the ontological newness of the computer game. It catches the missing both fields of philosophy and game studies. More than what it means beyond the philosophy of computer game. The concept indicates that the game is an object of thoughts and consists essentially of elucidations. It involves the rule in order to conduct everything can be thought and said clearly. The rule is a discipline intended to produce a specific characteristic or pattern of action and is especially a training that produces moral, physical or mental development towards a particular direction. It implies that the game with BCI as healthcare information design is philosophizing on two performances making the rule and simultaneously obeying the rule.

The metaphor is a crucial point that prescribes the double performance of the rule. In BCI game as healthcare information design using brain information, the rule conducts a process of metaphorical thinking. The metaphor comes from the Greek 'metaphora,' in which 'meta' is a tenor (or moving) and 'phora' is a vehicle (or vans). It is a rhetorical trope defined as a comparison (or analogy) for an unrelated object. The tenor is an object being described, and a vehicle is an object borrowing a description. In "Juliet is the sun," Juliet is a tenor and the sun becomes a vehicle. The rule of the game follows the rule of metaphor in which both objects (the user and the game or the user and the selected character) simultaneously must be considered. When a user is playing a game, the user and the game or the user and the selected character also have a mapping of the concepts as a tenor and a vehicle. The rule of the game becomes a metaphor performing an interaction between rules and establishes similarity and difference of objects.

The narrative of the game with BCI as healthcare information design outcomes is imported by this metaphorical performance of the rule. As a moving van, the metaphor must be found out in a performance of thoughts and events. In other words, the performance of the rule can be considered as the narrative in which series of thoughts and events are involved. For example, the word 'game' is an ambiguous term that the narrative remains inactive. When someone uses the word 'game' as a noun or a verb, it becomes a metaphor that contains a rule of 'similarity and difference' in the performance of thought and events. At this moment, we are locked up in the obscuring story of the word 'game' that needs to be overcome, and the narrative is generated in the performance. In the philosophizing game with BCI, the performance of the rule shows that there is an apparent ontological difference (or a method of existence) between the narrative of the game and the narrative of the literary.

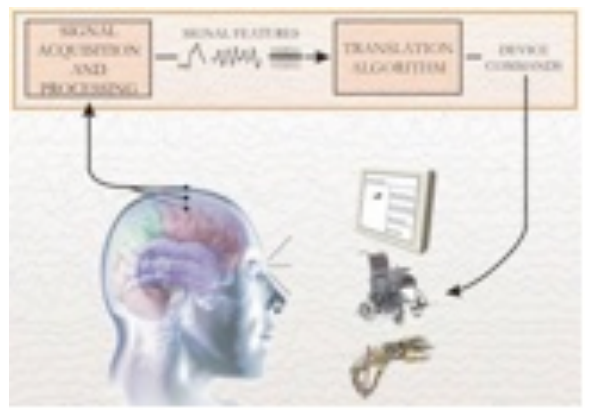

Figure 2. Healthcare Information Design: $\mathrm{BCl} 2000$ Platform of Racing Car Game with $\mathrm{BCl}$

In the case of Racing Car Game, the narrative is replaced by the processing of the signal. Racing Car Game's system is implemented under BCI2000 platform (general purpose software in BCI research). Graphical software visualizes concentration index, and hardware module controls the velocity of a racing car. BCI2000 is a general-purpose system for BCI research and development (Fig.2). It can also be used for data acquisition, stimulus presentation, or brain observation applications. BCI2000 consists of a Signal Acquisition module that acquires brain signals from g.USBamp or g.MOBIlab+devices. These raw signals are visualized and stored to disks and submitted to the Signal Processing module. The Signal Processing module extracts signal features and translates them into the device command. Its commands are used by the Applications module to generate collaborative action of human and technology.

As a case of the philosophizing BCI game, Racing Car Game presents that the computer game using bioinformation originated from healthcare design outcomes is the moving. The literary work has a fixed story that is written by the author, and the reader reads it. The computer game, however, surely requires the user's action, and the collaborative action of humans and computer even constructs the game itself.

Here the interesting point of the philosophizing BCI game using brain information as healthcare information design outcomes is that we do not just see that things move in the game, but we see them moving in it, and this is because we ourselves move it. In other words, BCI game as a meta-design using healthcare information is not the still of moving things, but the moving of moving things. It shows that there is no coherent and inherent relevance in the game. Thus, it reframes the way of knowing and decolonizes the power of knowledge system. 
Arthur Danto said that "We refer to Voltaire only with reference to why we see the cloud as we do, not with reference to why the cloud is the way we see it."[6] The ontological difference (or the existence) is caused by the experience of reality, but causality and reference are in front of undetermined (or being determined) experience. It is not undetermined causality and reference, but veridical experience. The philosophizing BCI game presents that we have to question the way of knowing, that is, the rule of the knowledge game.

\section{More Than What It Means: Knowledge Game}

\subsection{Context: Use of BCI Game 1.}

The philosophizing game with BCI as healthcare information design outcomes reconsiders the conflict between the game and the narrative. What is a real game? What is the narrative of the game? Is it agreed to obey the theory of the literary narrative? For a long time, these questions have been controversial. Especially, in the relationship between the game and the narrative, Narratology and Ludology have different perspectives. The former is based on the traditional narrative theory of the literary while the latter is claimed that the game should not be viewed as an extension of the traditional narrative.

BCI game using brain information originated from healthcare design reconciles two theoretical frames. On the one hand, it embraces Narratology that is interested in the shows (or traces) of the game. According to Mieke Bal, the narrative contains both an actor and a narrator; it also should contain three distinct levels consisting of the 'text', the 'story', and the 'fabula'; its contents should be a series of connected events caused or experienced by actors [7]. As a level of the narrative, the 'text' is a totality of structures with language signs, the 'story' represents the 'fabula,' and the 'fabula' is continuous events with a logical, temporal and historical connection that is caused or experienced by the actor. In short, the narrative of the philosophizing BCI game is a 'series of connected events' caused or experienced by actors' and it requires both an 'actor and a narrator' as a narrative condition.

On the other hand, BCI game concerns Ludology focusing on the rule as a cause and an experience, and the game itself that defines a winner and a loser as the result of it. It presents that the game with BCI produces a sequence of events, but it is not just the narrative that makes a continuous story or a formal development. It has the simulation as a representational and rhetorical tool, which is a way of portraying reality.

At this point, the philosophizing game with BCI is an inevitable risk in trying to clarify the potential and synergistic effects of Narratology and Ludology. It reveals that the conflict between the game and the narrative depends upon a 'political pedagogy'; it challenges an academic, scholastic and scientific meaning. Thomas S. Kuhn distinguishes 'context of discovery' from 'context of justification.' How is this distinction mystified? He calls it the "context of pedagogy."'[8] It is similar to the fact that the Foucault's Pendulum itself represents the scientific and rational reason of human, but the moving earth as an exploring object is full of endless mysteries. It recalls that the knowledge game is useful in the classification, but the game always transcends it.

\subsection{Interpretation: Use of $\mathrm{BCl}$ Game 2.}

The philosophizing BCI game presents that there is no distinction between a random and a systematic. The understanding itself is a state using the rule. The problem is not the meaning, but how to use the rule. The correct use of the rule is an important term in Ludwig Wittgenstein's philosophy [9].

Let's consider that a user A and a user B are playing a game of numbers. A has written down numbers $1,5,11$, 19. After A writes the number 19, B finds out a formula an $=n^{2}+n-1$, and says, "Yes, I know the next number." This process is a perfect imagination. It may be thought to have the narrative and to get hold of the mental process of understanding that seems to be hidden behind the visible accomplishment. We, however, do not succeed in getting the narrative and the mental process. Since, it surely doesn't mean a simple understanding that ' $\mathrm{B}$ understands the rule of the series,' and we would have endless questions as a chain of reason that comes to the end; what is the understanding? Why should it be understood?

If there has to be something behind the utterance of a formula, it is a 'particular circumstance' that we are trained to do so. There is no understanding with a mental process that is originated from a pure operation of the body like the sickness. When we are obeying the rule of the philosophizing computer game with BCI as healthcare information outcomes, we can have a special experience. But it is also the circumstance under which we had such an experience that justifies us in such a case that we understand and that we know how to go on. This is the reason why we have to call us not the player or the gamer but the 'user'!

Obeying the rule, giving the order and playing the game are merely customs as we are trained to do so. Therefore, there is no place for the narrative in it. If there, however, is something remained, it is not the narrative, but an 'interpretation of the rule.' When we should comment on the situation that someone is playing the game with BCI, the game is translated into a series of actions according to certain rules. In other words, the BCI game procedure is translatable by the rule, since every action of the user is determined by the rule. Thus, the narrative of BCI game is a merely 'surplus of this interpretation.' Unlike narrative of the literary narrative, the interpretation of BCI game is endless, and it just 
merely defines a winner and a loser. Thus, Wittgenstein said that "if we dwell upon the rule, and do try to get beyond it, the difficulty here is: to stop."'[10]

\section{Inside Out}

\subsection{The Void Subject of BCI Game}

In the knowledge game of relationships between we humans and computer, BCI game intervenes on the traditional knowledge, specially, through the problematic of subject. Arguably, BCI game using brain waves, EEG as healthcare information design outcomes, questions that can the user be a subject in the knowledge game?

Edgar Allen Poe's mystery, 'The purloined letter' provides a good point to understand of the problematic of subject in BCI game. Poe's novel, 'The purloined letter' is a kind of game for finding and returning the love letter that the Queen has stolen. Unlike other mysteries, this novel shows the end that the robber is the minister D. At the beginning of the game, we know the result of the game and the problem is already solved. However, how does the game sustain the tension? So far as Poe's labors extend, the subject of the novel keeps changing by several characters; the private detective Dupin, a friend of the Dupin's, the Parisian police Monsieur G, the King and Queen and the minister D.

Who is a real subject in Edgar Allen Poe's mystery? It is the letter! In the novel, the finders searched the house itself and divided its surface into zones with numbers and even examined the moss between the bricks. Nevertheless, they could not find the letter. What is the reason? Poe gives examples that "there is a game of puzzles, which is played upon a map. A novice in the game generally seeks to embarrass his opponents by giving them most minutely lettered names; but the adept selects such words as stretch, in large charters, from one end of the chart to the other." It shows that these like the overlarge lettered signs escape observation by dint of being excessively obvious. In other words, we don't find it because we do not know what the letter is. In the end of the novel, the detective Dupin found the letter at the most obvious place in the apartment of minister D. This is not due to the ingenuity of Dupin, but to the structure of things. Dupin constantly speculates the symbol and sees the letter in the same eye level as the Queen had been put the letter in the previous place.

What, after all, is the letter? The letter leads us to change the seat of a subject. That is so called, intersubjectivity. The letter is a signifier that has both ways of the presence and the absence. We can find it in the symbol that nobody entirely owns it. In other words, the letter is a substitution of the desire, and it flies beyond all significations. The Odyssey of the letter is endless. In the Seminar, Jacques Lacan said that "Eat your Dasein!" and "like Thyestes to eat his own children and that, after all, is what we have to deal with every day, each time the line of symbols reaches its terminal point."

BCI game as meta-design of healthcare information design recalls a drama of Atreus and Thyestes about the endlessly fateful circle of revenge and hate. 'Eating your Dasein' means an inevitable fate of us, it is the circle that Atreus killed the Thyestes's son, served Thyestes with the son's flesh and Thyestes had no choice but to eat it. The philosophizing BCI game represents the flying letter in Poe's novel, and the flying letter represents the circle, the destiny. When BCI game (the letter) stimulates us with the chain of our desires, we think that we are operating it, but BCI game (the letter) always reaches its destination, the Symbol.

Therefore, BCI game is the play of the Symbol, the desire is a working engine of the game, and the desiring user can never become a real subject of the game. The void subject of BCI game reminds of "the destiny of being as the forgetting of being" as Bernard Stiegler's meditation [11]. It reveals that the human being is marked by an originary absence of origin, a fundamental lack of qualities.

\subsection{Invagination}

The philosophizing computer game with BCI as healthcare information design outcomes is a 'Don Quixote.' Like Miguel de Cervantes's “Don Quixote De La Mancha" that is the first modern work of literature, the computer game shows us that the rule of similarity and difference makes sport of our reason endless. Today, the computer game breaks off its old kinship with the literary narrative and it exactly marks the point converging madness and imagination. Michel Foucault defines that "The madman brings similitude to the signs that speak it, whereas the poet loads all signs with a resemblance that ultimately erases them."[12] The madman and the poet share the rule of the extreme point of our reason.

The philosophizing BCI game also has an ambivalence of the philosophy and game. The collaborative action of humans and computer involves the decolonizing knowledge. In Racing Car Game, the collaborative action of "We" human-and-technology becomes an imagination itself. It considers the collaborative action of "We" human-and-technology as both knowledge of practical arts and practical arts themselves. Thus, BCI game constituted by the collaborative action of "We" humanand-technology stimulates a network of conceptual relations rather than merely perceptions of the haptic and sensory aspects of interactive game design.

\section{Acknowledgements.}

This work was supported by the National Research Foundation of Korea Grant funded by the Korean Government (NRF2014S1A5B8044097). 


\section{References}

[1] Horkheimer, M. and Adorno, W.T. (2002) Dialectic of Enlightenment, (California: Stanford University).

[2] Cho, H.K and Yoon, J.S. (2009) The Performative Art: The Politics of Doubleness. LEONARDO, 42 (3): 282-283.

[3] Cho, H.K. (2013) Aesthetics of "We" human-andtechnology. Arts and Technology, LNICST, 116: 97-104.

[4] Cho, H., Luke, T. W. and Yoon, J. (2016), Decolonizing knowledge: Politics and the aesthetic of "We" human-andtechnology, Technoetic Arts: A Journal of Speculative Research, 14 (3): 175-185.

[5] Wittgenstein, L. (2005) Tractatus Logico-Philosophicus, (New York: Routledge)

[6] Danto, A. (2001) Moving Pictures, In: Philosophizing Art. (California: California University Press).

[7] Bal, M. (1985) Narratology: Introduction to the Theory of Narrative (Toronto: Toronto University Press).

[8] Kuhn, S. T. (2013) Objectivity, Value Judgment, and Theory Choice, In: Arguing about Science (New York: Routledge).

[9] Wittgenstein, L.(2005) Philosophical Investigations (Oxford: Blackwell).

[10] Wittgenstein, L. (2006) Following a Rule. In: The Wittgenstein Reader (Oxford: Blackwell).

[11] Stielger, B. (1998) Technics and Time 1: The fault of Epimetheus (California: Stanford University Press).

[12] Foucault, M. (2002) The Order of Things (New York: Routledge). 